Supporting Information

\title{
Beyond the Nucleophilic role of Metal-Boryl complexes in Borylation Reactions
}

\author{
Xueying Guo, ${ }^{a}$ Tilong Yang, ${ }^{a}$ Fu Kit Sheong, ${ }^{\text {a,b* }}$ and Zhenyang Lin ${ }^{a *}$

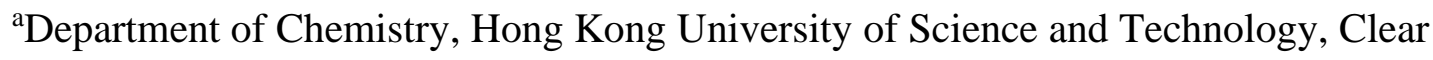 \\ Water Bay, Hong Kong, China \\ bInstitute for Advanced Study, Hong Kong University of Science and Technology, \\ Clear Water Bay, Hong Kong, China
}

\section{Table of Content}

Figure S1. Energy profiles calculated for Paths A and B related to the $\mathrm{PhCHO}$ insertion into (NHC)Cu-Bpin

Figure S2. PIO pairs calculated for Cu-a-BC_TS1

Figure S3. Energy profiles calculated for Paths A and B related to the $\mathrm{PhCHO}$ insertion into (NHC) $\mathrm{Cu}-\mathrm{BPh}_{2}$

Figure S4. Energy profiles calculated for Paths A and B related to the $\mathrm{PhCHO}$ insertion into (NHC)Au-BPh 2

Figure S5. PIO pairs calculated for Au-b-BO_TS2

Figure S6. Energy profiles calculated for Paths A and B related to the $\mathrm{PhCHO}$ insertion into (NHC)Au-Bpin

Figure S7. Energy profiles calculated for Paths A and B related to the $\mathrm{PhCHO}$ insertion into $\left(\mathrm{PH}_{3}\right)_{3} \mathrm{Rh}-\mathrm{Bpin}$

Figure S8. PIO pairs calculated for Rh-a-BO_TS

Figure S9. Energy profiles calculated for Paths A and B related to the $\mathrm{PhCHO}$ insertion into $\left(\mathrm{PH}_{3}\right)_{3} \mathrm{Rh}-\mathrm{BPh}_{2}$ S6

Figure S10. FMOs calculated for $\mathrm{PhCHO}$, (NHC)Cu-Bpin and ( $\mathrm{NHC}) \mathrm{Cu}-\mathrm{BPh}_{2} \quad \mathrm{~S} 6$

Figure S11. FMOs calculated for $\mathrm{PhCHO}$, (NHC)Au-Bpin and (NHC)Au- $\mathrm{BPh}_{2} \quad \mathrm{~S} 7$

Figure S12. FMOs calculated for $\mathrm{PhCHO},\left(\mathrm{PH}_{3}\right)_{3} \mathrm{Bpin}$ and $\left(\mathrm{PH}_{3}\right)_{3}-\mathrm{BPh}_{2} \quad \mathrm{~S} 7$

Table S1. Calculated imaginary frequencies, electronic energies, and thermal corrections to energies for all the transition states 


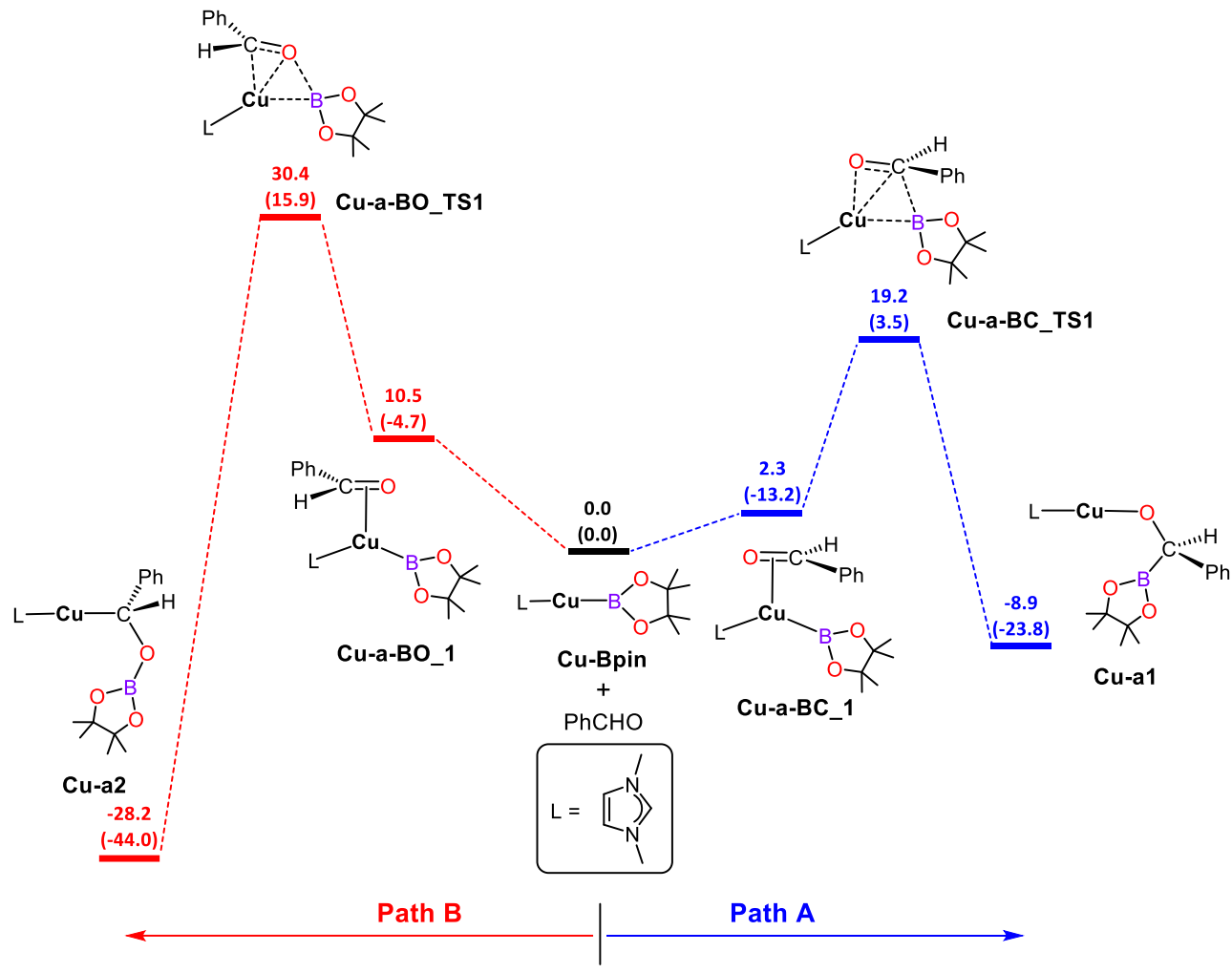

Figure S1. Energy profiles calculated for Paths A and B related to the $\mathrm{PhCHO}$ insertion into (NHC)Cu-Bpin. Relative free energies and electronic energies (in parenthesis) are given in $\mathrm{kcal}^{\bullet} \mathrm{mol}^{-1}$.
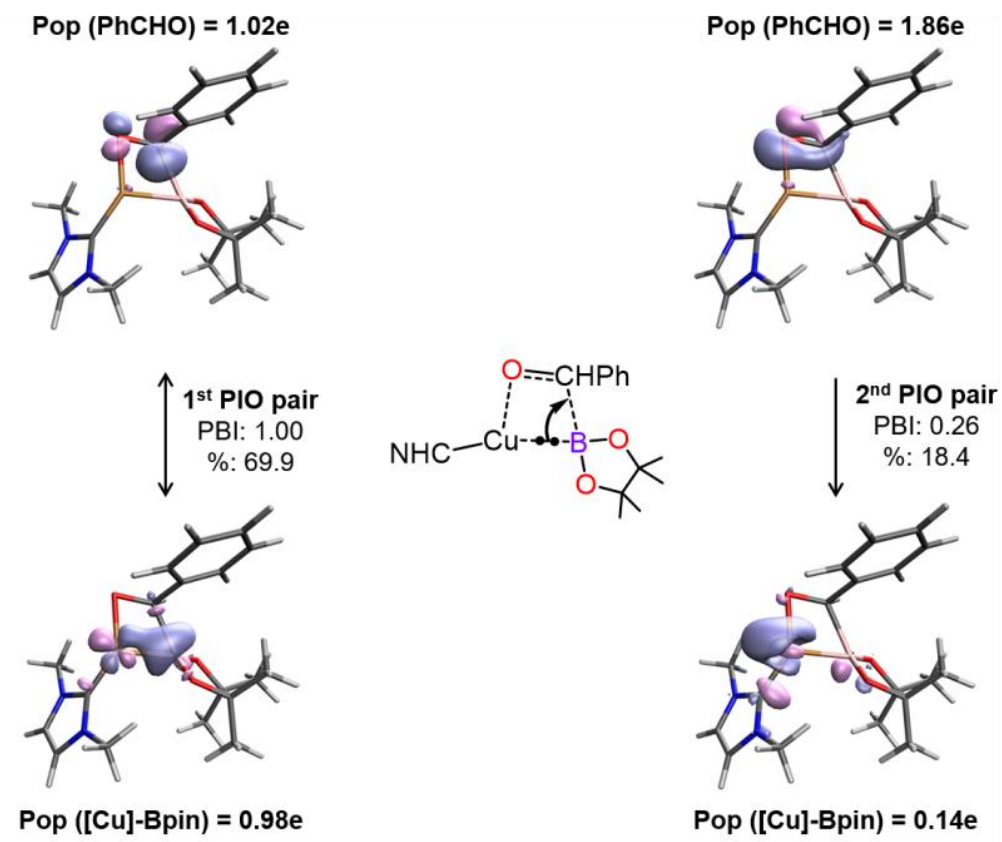

Figure S2. Dominant PIO pairs calculated for Cu-a-BC_TS1. The two presented PIO pairs account for $>85 \%$ of total orbital interactions between the two fragments. The $1^{\text {st }}$ PIO pair indicates a prominent interaction between the boryl $\sigma$-bonding pair and the aldehyde $\pi^{*}$ orbital, accounting for a major portion of orbital interactions. The $2^{\text {nd }}$ PIO pair indicates the donation from aldehyde oxygen to the metal s orbital. (Pop: PIO population of the indicated fragment; PBI: PIO-based bond index; \%: Percentage contribution of the PIO pair to the total orbital interactions) 


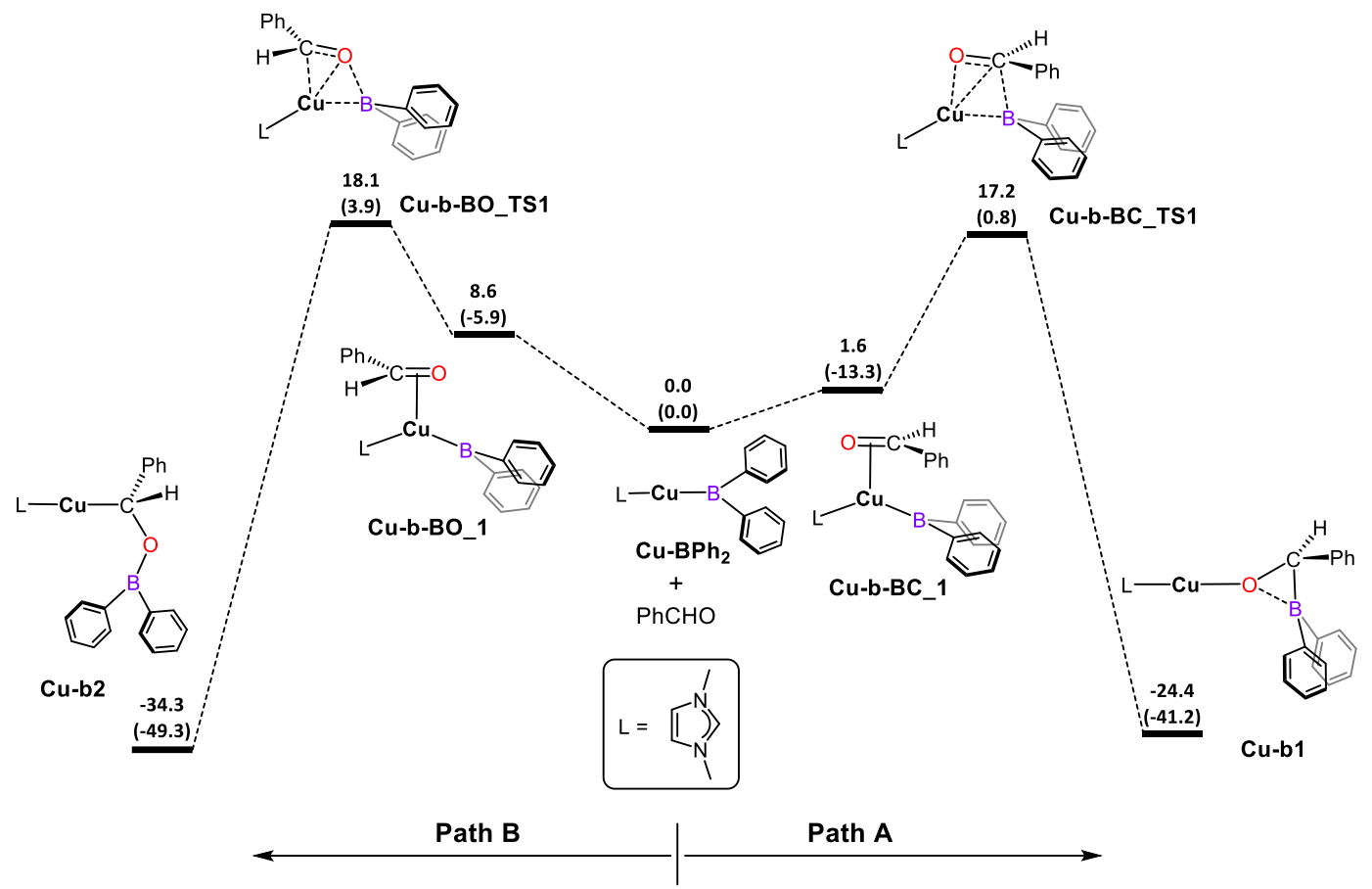

Figure S3. Energy profiles calculated for Paths $\mathrm{A}$ and $\mathrm{B}$ related to the $\mathrm{PhCHO}$ insertion into $(\mathrm{NHC}) \mathrm{Cu}-\mathrm{BPh}_{2}$. Relative free energies and electronic energies (in parenthesis) are given in $\mathrm{kcal}^{-} \mathrm{mol}^{-1}$.

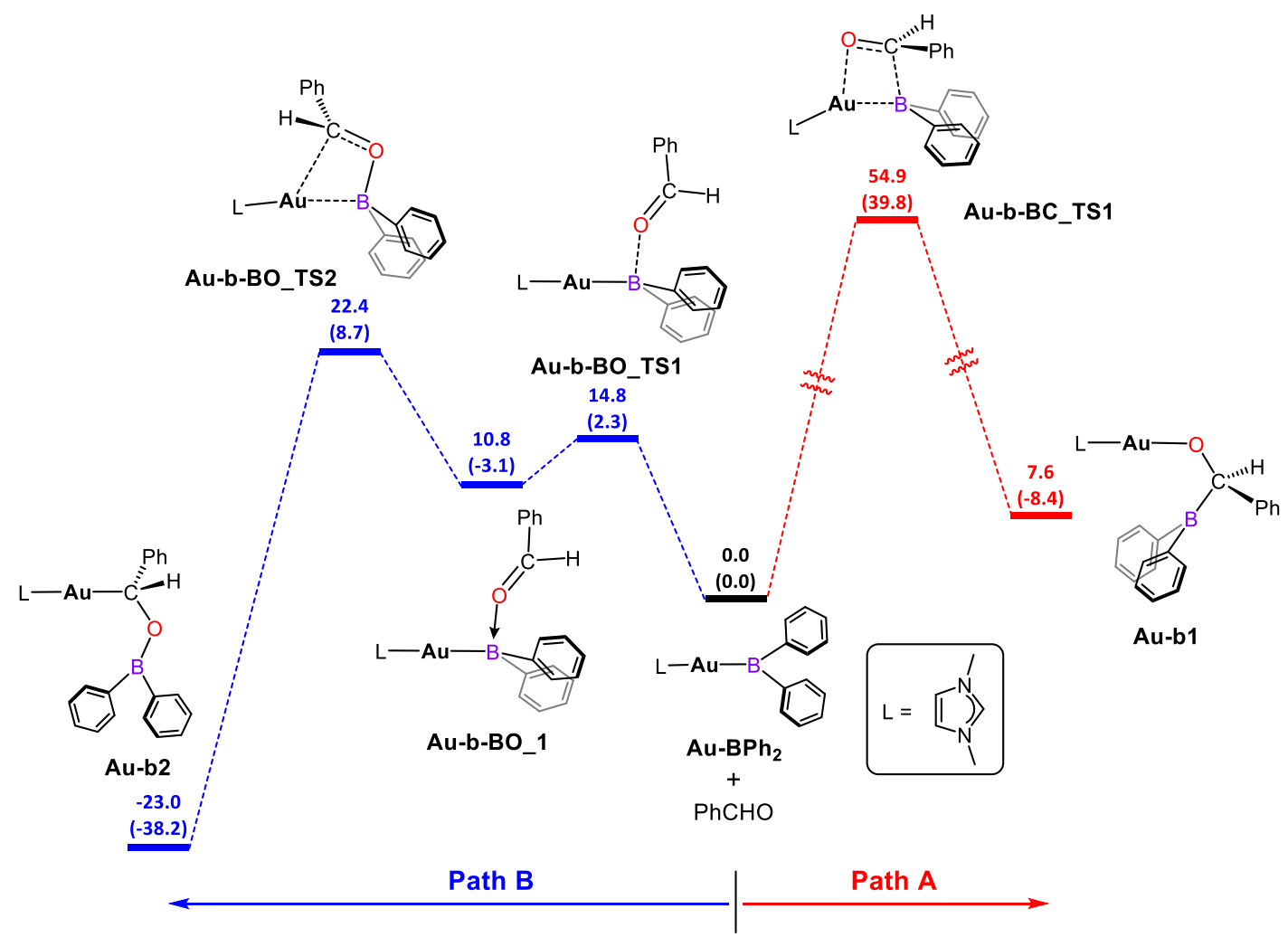

Figure S4. Energy profiles calculated for Paths $\mathrm{A}$ and $\mathrm{B}$ related to the $\mathrm{PhCHO}$ insertion into (NHC)Au-BPh 2 . Relative free energies and electronic energies (in parenthesis) are given in kcal $\bullet \mathrm{mol}^{-1}$. 

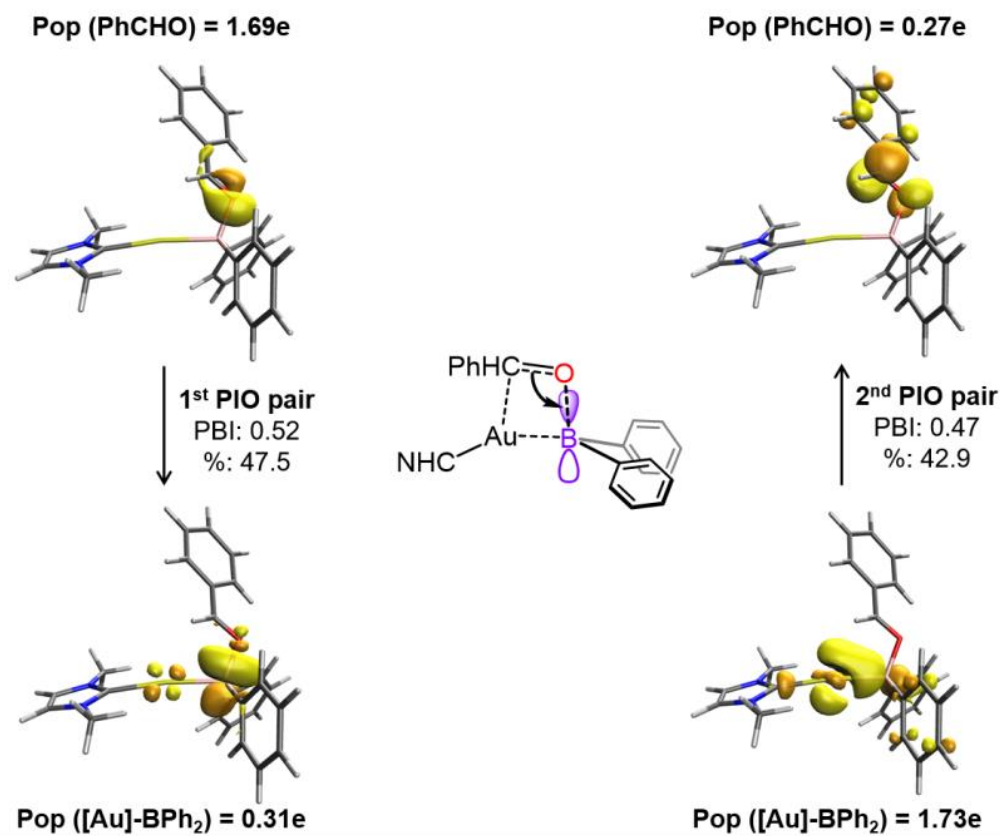

Figure S5. Dominant PIO pairs calculated for Au-b-BO_TS2. The two presented PIO pairs account for $>85 \%$ of total orbital interactions between the two fragments. The $1^{\text {st }}$ PIO pair indicates the donation from aldehyde oxygen to the boron "empty" $p$ orbital. The $2^{\text {nd }}$ PIO pair indicates the donation of Au-B bonding to the aldehyde $\pi^{*}$ orbital. It is clear that the "empty" p orbital of boron plays a significant role in this case, which is very different from the one shown in Figure S2.

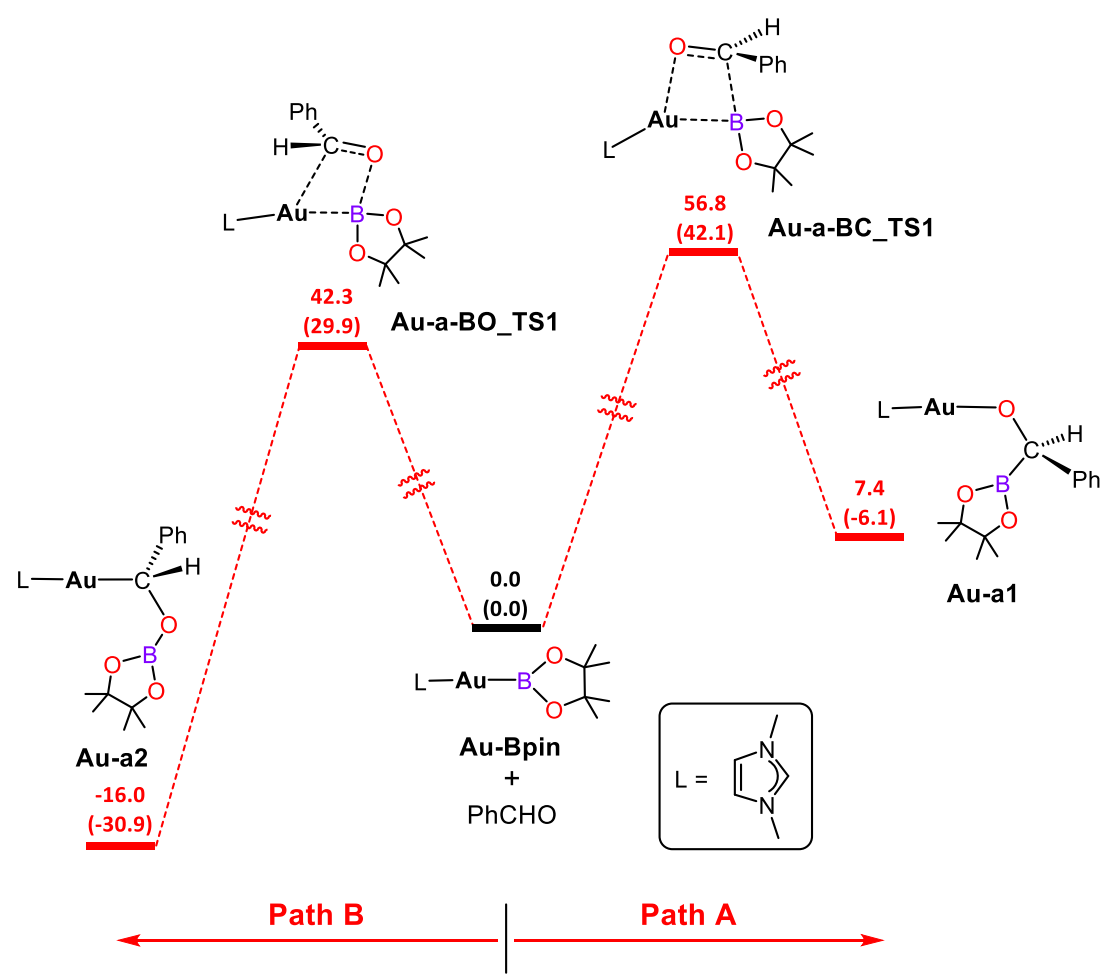

Figure S6. Energy profiles calculated for Paths A and B related to the $\mathrm{PhCHO}$ insertion into (NHC)Au-Bpin. Relative free energies and electronic energies (in parenthesis) are given in $\mathrm{kcal}^{\bullet} \mathrm{mol}^{-1}$. 


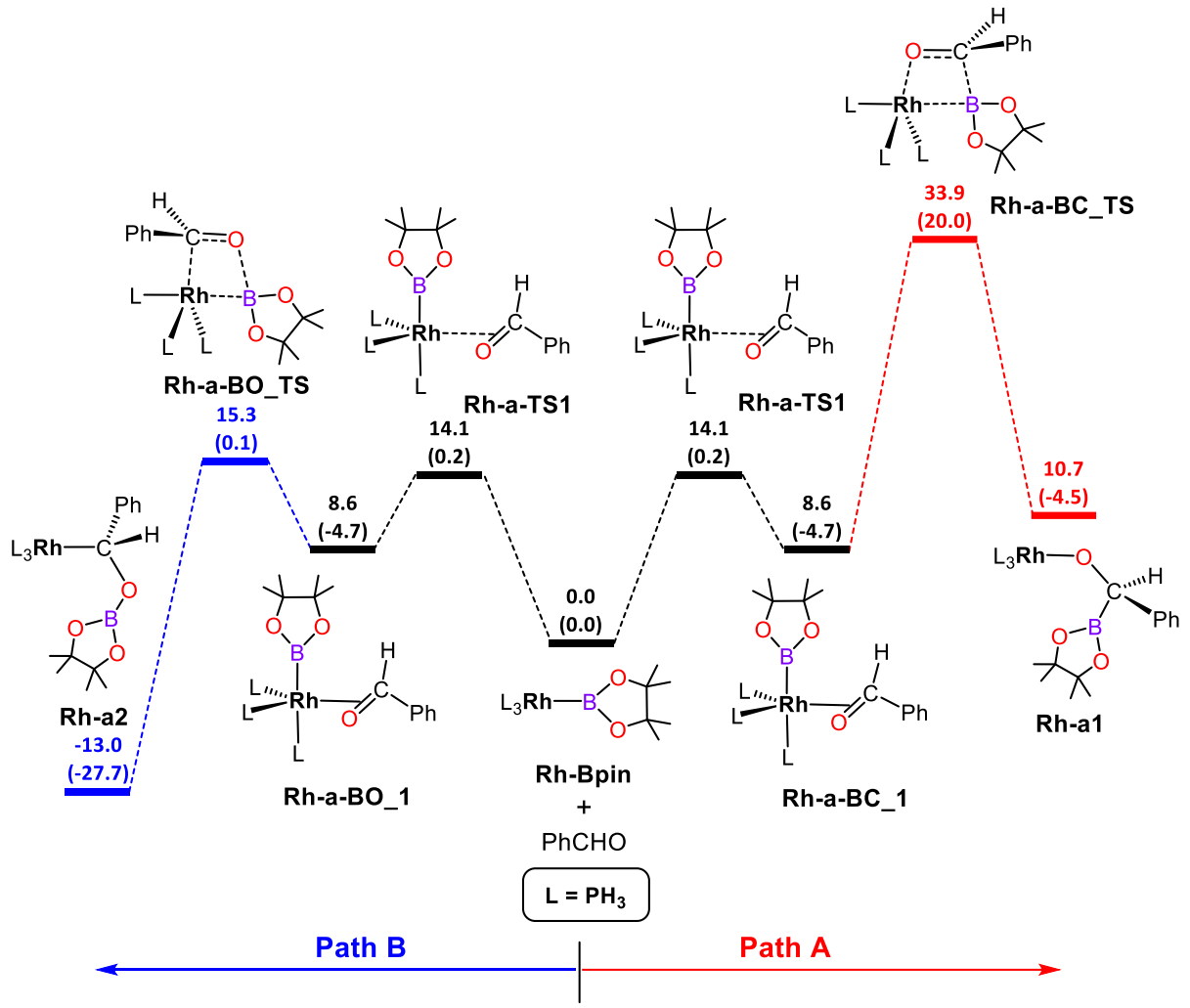

Figure S7. Energy profiles calculated for Paths A and B related to the PhCHO insertion into $\left(\mathrm{PH}_{3}\right)_{3} \mathrm{Rh}$-Bpin. Relative free energies and electronic energies (in parenthesis) are given in $\mathrm{kcal} \bullet \mathrm{mol}^{-1}$.

$\mathrm{Pop}(\mathrm{PhCHO})=0.70 \mathrm{e}$
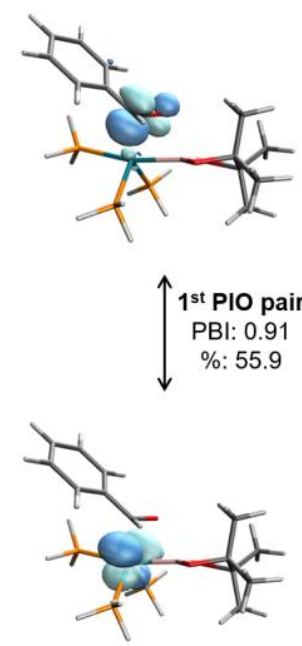

Pop $([R h]-B p i n)=1.30 \mathrm{e}$
$\mathrm{Pop}(\mathrm{PhCHO})=1.74 \mathrm{e}$
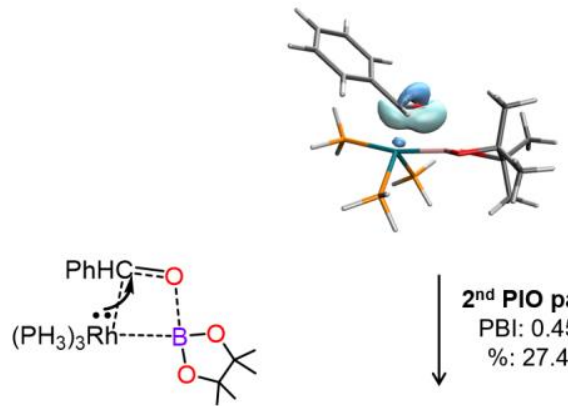

$2^{\text {nd }}$ PIO pair
PBI: 0.45
$\%: 27.4$

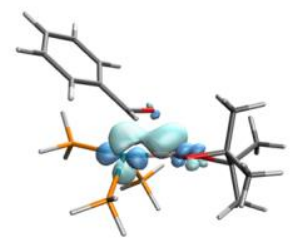

Pop $([R h]-B p i n)=0.26 e$

Figure S8. Dominant PIO pairs calculated for Rh-a-BO_TS. The two presented PIO pairs account for > $80 \%$ of total orbital interactions between the two fragments. The $1^{\text {st }}$ PIO pair indicates a prominent interaction between the Rh d orbital and the aldehyde $\pi^{*}$ orbital, accounting for a significant portion of orbital interactions. The $2^{\text {nd }}$ PIO pair indicates the donation from aldehyde oxygen to the Rh-B antibonding (partly mixed with boron p orbital). 


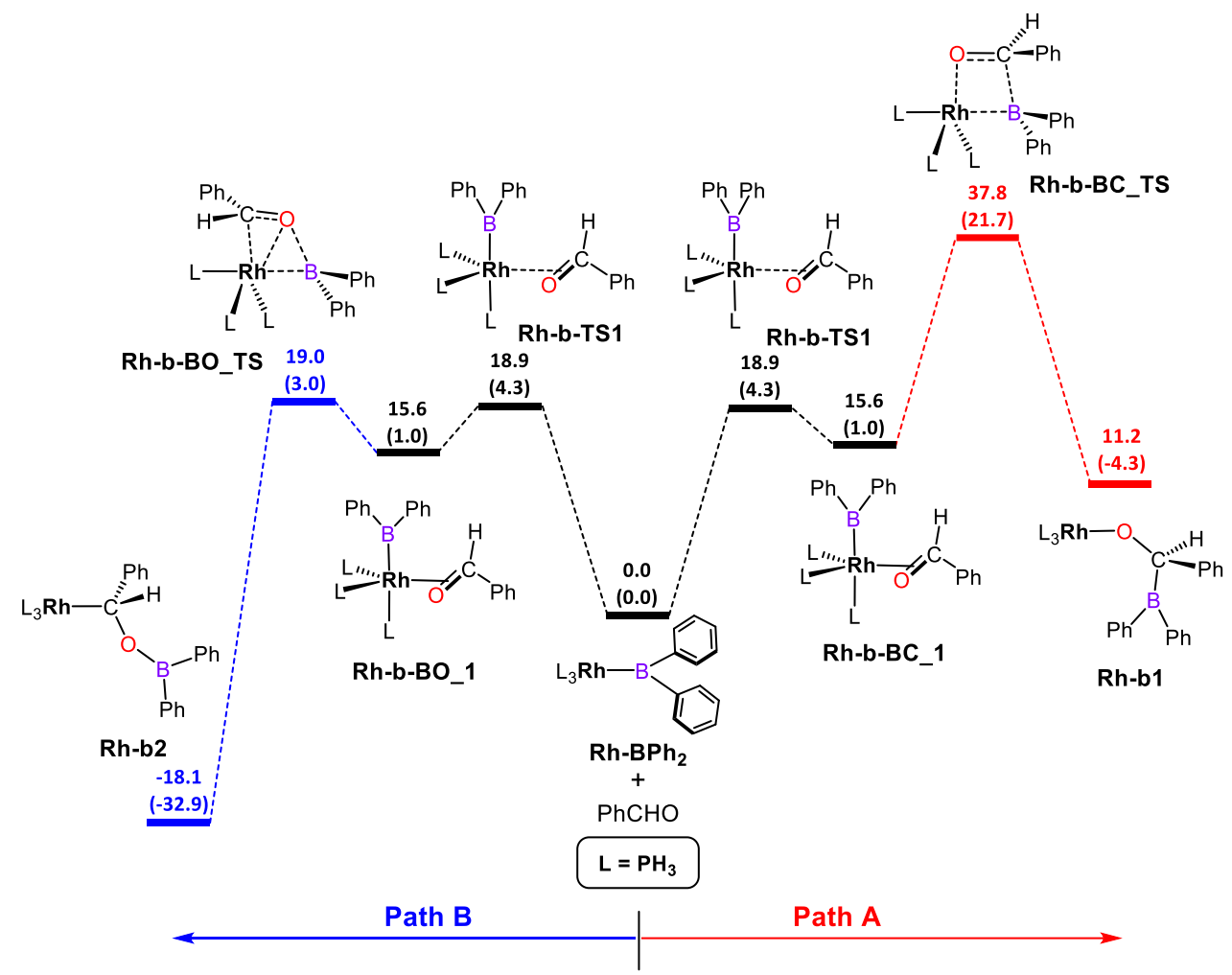

Figure S9. Energy profiles calculated for Paths $\mathrm{A}$ and $\mathrm{B}$ related to the $\mathrm{PhCHO}$ insertion into $\left(\mathrm{PH}_{3}\right)_{3} \mathrm{Rh}-\mathrm{BPh}_{2}$. Relative free energies and electronic energies (in parenthesis) are given in kcal $\bullet \mathrm{mol}^{-1}$.

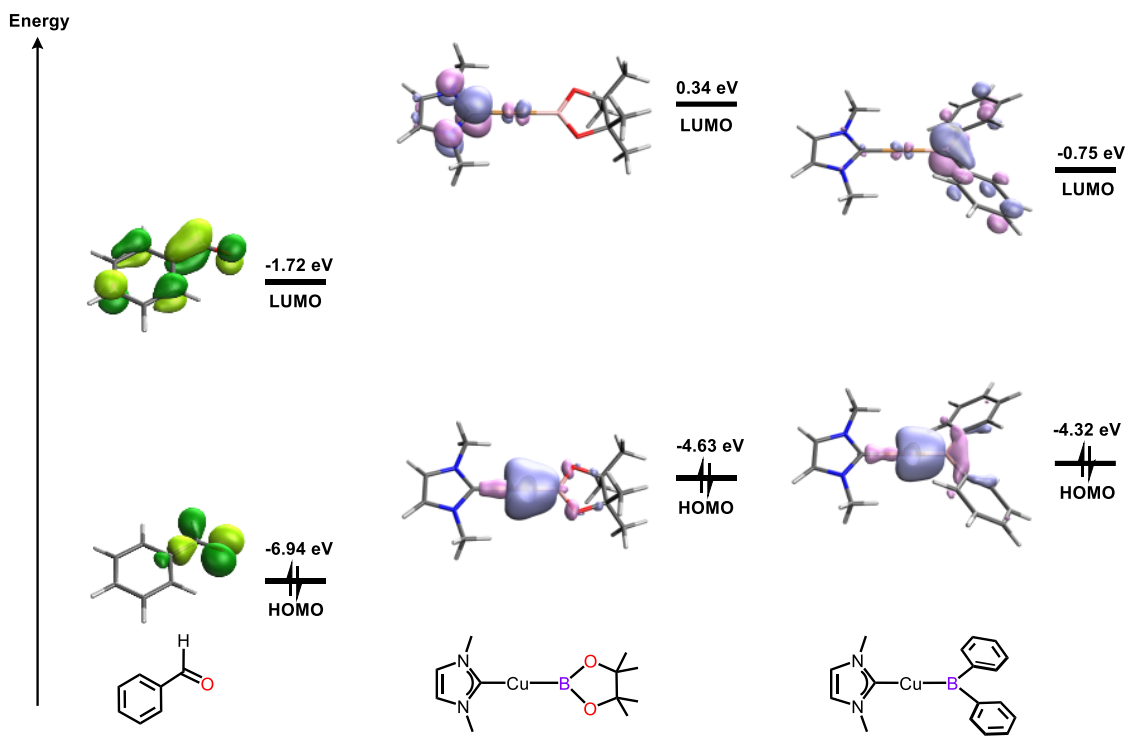

Figure S10. FMOs calculated for $\mathrm{PhCHO},(\mathrm{NHC}) \mathrm{Cu}-\mathrm{Bpin}$ and $(\mathrm{NHC}) \mathrm{Cu}-\mathrm{BPh}_{2}$. 


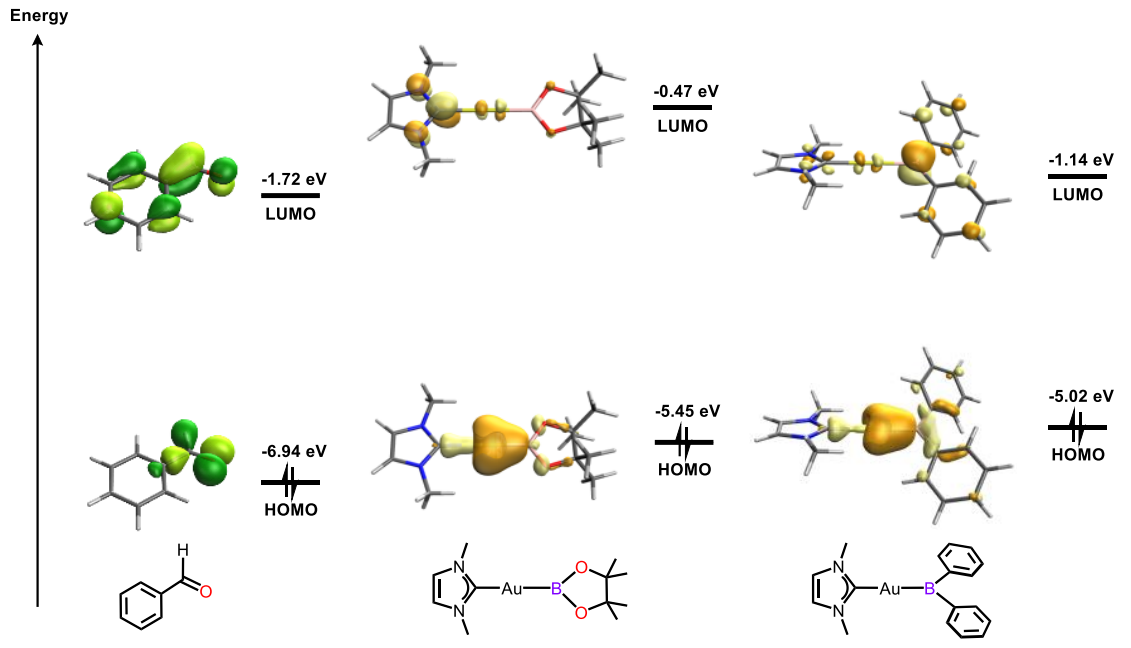

Figure S11. FMOs calculated for $\mathrm{PhCHO}$, (NHC)Au-Bpin and (NHC)Au- $\mathrm{BPh}_{2}$.

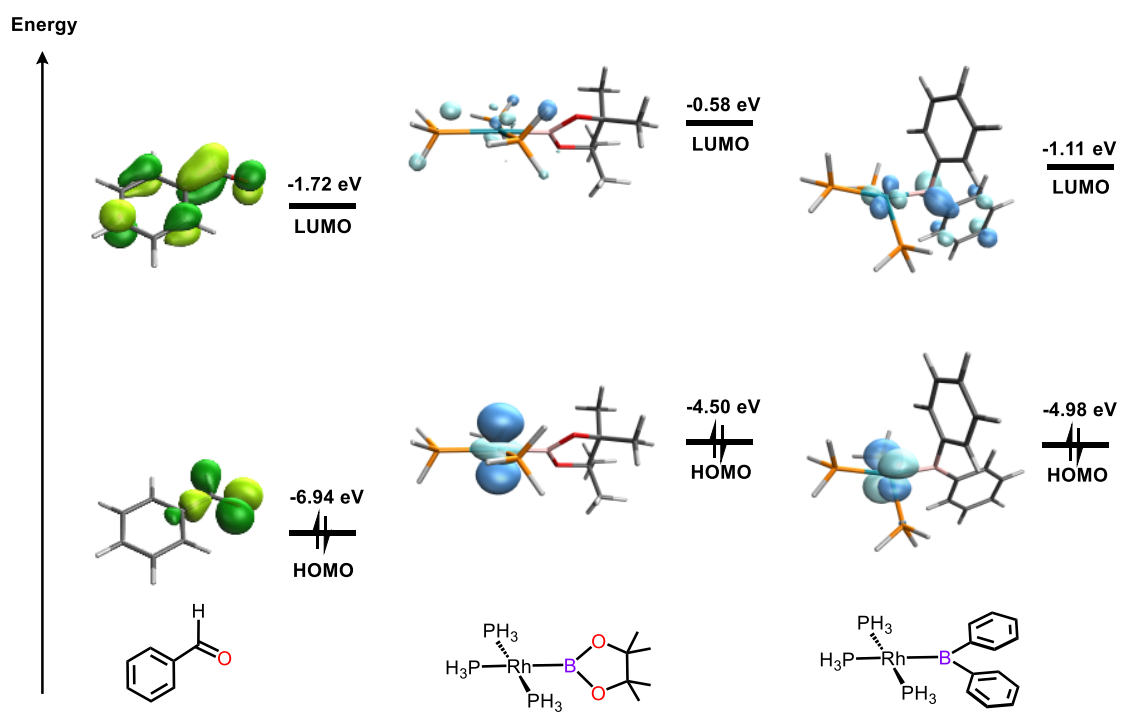

Figure S12. FMOs calculated for $\mathrm{PhCHO},\left(\mathrm{PH}_{3}\right)_{3} \mathrm{Rh}-\mathrm{Bpin}$ and $\left(\mathrm{PH}_{3}\right)_{3} \mathrm{Rh}-\mathrm{BPh}_{2}$. 
Table S1. Calculated imaginary frequencies, electronic energies, and thermal corrections to energies for all the transition states.

\begin{tabular}{cccc}
\hline Species & $\begin{array}{c}\text { Imaginary } \\
\text { Frequency }\end{array}$ & $\begin{array}{c}\text { Electronic Energy } \\
\left(\mathbf{c m}^{-1}\right)\end{array}$ & $\begin{array}{c}\text { Thermal } \\
\text { Correction to }\end{array}$ \\
\hline Cu-a-BC_TS1 & -231.38 & -2702.159101 & 0.365179 \\
Cu-a-BO_TS1 & -390.88 & -2702.139381 & 0.363276 \\
Cu-b-BC_TS1 & -223.35 & -2779.045709 & 0.366783 \\
Cu-b-BO_TS1 & -207.39 & -2779.040679 & 0.363079 \\
Au-a-BC_TS1 & -316.62 & -1197.454706 & 0.361957 \\
Au-a-BO_TS1 & -529.38 & -1197.474006 & 0.358095 \\
Au-b-BC_TS1 & -314.66 & -1274.337411 & 0.362653 \\
Au-b-BO_TS1 & -105.10 & -1274.397274 & 0.358530 \\
Au-b-BO_TS2 & -108.05 & -1274.386987 & 0.360362 \\
Rh-a-TS1 & -77.47 & -1896.958928 & 0.314494 \\
Rh-a-BC_TS & -186.78 & -1896.927904 & 0.315447 \\
Rh-a-BO_TS & -186.30 & -1896.959527 & 0.317312 \\
Rh-b-TS1 & -79.86 & -1973.833364 & 0.316148 \\
Rh-b-BC_TS & -203.94 & -1973.805631 & 0.318440 \\
Rh-b-BO_TS & -53.39 & -1973.835358 & 0.318241 \\
\hline
\end{tabular}

